\title{
E-BRIEF
}

November 20, 2014

FINANCIAL SERVICES

\section{A Speedier and More Efficient Payments System for Canada}

by

Mati Dubrovinsky

- Reviews of the Canadian payments system find that the needs of its users, especially businesses, are not adequately met. The system does not offer a standardized data format for accounting information, and confirmation and funds availability are slow.

- The Large Value Transfer System and the Automated Clearing and Settlement System, for lower value transfers, are used for inter-bank payments. While the large-value system has some standardized accounting data, the low value system is more limited.

- The Canadian Payments Association, under the guidance of Finance Canada, could channel all inter-bank transfers through the Large Value Transfer System, and discontinue the low-value system. This would reduce the costs of payments processing for Canadian businesses, making them more competitive globally.

The two most recent reviews of the Canadian payments system - by the federal Task Force for the Payments System Review (2011) and the Canadian Payments Association (2008) - have found that the needs of payments' system users, especially businesses, are not being adequately met. Specifically, internal payments processing and accounting reconciliation for businesses tend to be costlier and less automated than what might be expected, given the current state of technology. Additionally, both consumers and businesses express dissatisfaction with the speed of funds availability, particularly when compared to other countries.

I am grateful for fruitful conversations with Thor Koeppl and helpful industry experts, as well as thoughtful and thorough comments of anonymous reviewers and the editor. 
In this E-Brief, I argue that an overhaul of the Large Value Transfer System, which is the Canadian system for clearing and settling large-value payments among participating financial institutions, could reduce participants' financial risk in processing low-value payments. As well, such an overhaul would result in lower paymentprocessing costs for Canadian businesses. In the end, this would enhance the global competitiveness of Canadian businesses, as well as the efficiency and safety of Canadian payments-system participants.

More recently, the Bank of Canada also recognized the need for a faster and more efficient payment regime and suggested that the best way to achieve this is to eliminate the existing unequal approach to low- and highvalue payments (Schembri 2014). This E-Brief agrees with that analysis and proposes a system that treats highand low-value payments in a more equal fashion.

\section{The Canadian Payments System Today}

In Canada, individuals primarily use the following instruments to pay when shopping in a retail store: cash, ${ }^{1}$ credit cards, Interac debit cards and cheques. ${ }^{2}$ Some retailers accept only a subset of these payment instruments. Pre-paid, or gift, cards, as well as other instruments, are significantly less common, and I do not discuss them here. ${ }^{3}$

Businesses use some of the above instruments to pay suppliers. Businesses also can register as billers with their bank or with a payments-service provider. ${ }^{4}$ This allows for direct bill payments or, more generally, electronic fund transfers (EFTs) directly into their bank accounts. Additionally, for a considerably higher fee, businesses and individuals can wire payments.

Finally, cheques are among major payments instruments for both businesses and individuals. When paying with a cheque, the payer provides a physical paper to the payee. The payee submits the cheque to his/her bank (some banks allow the submission of an electronic image scan). In the next stage, the payee's bank credits the payee's account and sends the cheque, either in a paper or an electronic format, to a cheque-processing firm. ${ }^{5}$ The processing firm scans all the paper cheques it receives and forwards them electronically to the payer's bank. Although the payee's bank credited the payee's account when it first received the cheque, the payee's bank will subsequently debit the payee's account in the amount of the cheque plus a fee if the payer's bank refuses to honour the payment.

1 Cash, while convenient for low-value purchases, is rarely used today beyond low-value retail payments, owing to its high handling costs. In 2011, for example, cash constituted less than 20 percent of value for retail transactions (Arango, Huynh, Fung and Stuber 2012). In this E-Brief, I deal mainly with payment instruments that use the CPA infrastructure to clear and settle. Cash does not require clearing and settlement.

2 Some Canadian credit card providers also offer debit cards. The market share of these "proprietary" debit cards is small, and they clear and settle over the issuer's network in a similar manner to proprietary pre-paid cards and credit cards.

3 For some businesses, some less common payment instruments, such as pre-paid cards, could account for a significant sales share. For the economy as a whole, however, these do not command a large volume or value of all payments. See https://www.cdnpay.ca/imis15/eng/Publications/News/eng/res/ns/remarks_senate_digital_currencies.aspx.

4 Throughout this E-Brief, I use "bank" to refer to any deposit-taking financial institution that is a direct participant in CPA's ACSS and the LVTS settlement systems. In isolated instances, however, "bank" could also imply a smaller deposit-taking institution that is not a direct participant.

5 Payment processors INTRIA (http://intriaitemsinc.com/) and Symcor (http://www.symcor.com/) handle the majority of cheques circulating in Canada. 
Individuals also may transfer funds to any Canadian bank account using the Interac e-Transfer service. PayPal, an online payment service, is also available to Canadian individuals and businesses.

\section{Clearing and Settlement}

Every payment involves a transfer of funds. Funds are stored in bank accounts. If a payer and a payee do not bank with the same institution, a transfer of funds from the payer's to the payee's bank must occur. These transfers take place using clearing and settlement infrastructure.

The Canadian Payments Association (CPA), a member-based non-profit organization, operates the clearing and settlement infrastructure responsible for 80 percent of the value and 55 percent of the total payments in the Canadian economy. ${ }^{6}$ Large banks and other deposit-taking institutions constitute the backbone of CPA membership and participate directly in its clearing and settlement arrangements. Smaller institutions must contract with direct participants to have access to CPA's clearing and settlement services. All direct participants keep a settlement account with the Bank of Canada, which adjusts these accounts to reflect the transfer information between participants it receives (Arjani and McVanel 2006).

\section{The Large ValueTransfer System (LVTS) ${ }^{7}$}

Established in 1999, the LVTS is a modern clearing and settlement system, which processes large value transfers between banks. Every transaction, or transfer, over the LVTS is a digital information package sent in the worldstandard format established by the Society for Worldwide Interbank Financial Transactions (SWIFT). The package includes the payment information and can include some remittance data as well (CPA 2013). ${ }^{8}$ The Bank of Canada and all LVTS direct participants involved in a transaction observe all information transmitted in real time, and every transaction is final and irreversible upon acceptance by the system, after it passes certain risk controls.

However, the Bank of Canada adjusts the settlement accounts only at the end of each business day - this is when settlement occurs. As a result, all transaction initiators essentially owe funds throughout the day. If some of the initiating participants default on their obligations, the entire Canadian financial system could suffer substantial losses.

The IVTS manages risk through the use of collateral, as well as other rules of operation. Currently, the IVTS allows funds to be transferred through two tranches. Tranche 1 limits each participant's net-debit position (the transfers it sent, net of those it received) to the collateral it pledged to the system, meaning every transfer is fully collateralized. Tranche 1 is used mainly for transfers to the Bank of Canada.

Tranche 2 arrangements take into account that the securities participants pledge as collateral cannot be used in other transactions. This makes collateral costly to the LVTS participants. The mechanism reduces collateral requirements in the following way: every participant wishing to receive transfers from participant A extends it a bilateral credit limit (BCL) for the day. Each participant that extends BCLs collateralizes 30 percent of its highest

6 See https://www.cdnpay.ca/imis15/eng/Publications/News/eng/res/ns/remarks_senate_digital_currencies.aspx, as well as Box 1 for a description of non-CPA clearing and settlement arrangements.

7 The exposition in this section is largely based on Arjani and McVanel (2006) and Engert, Gravelle and Howard (2008).

8 Remittance information contains all the accounting data - the payer's identity, the purpose of payment and more. 


\section{Box 1: Clearing and Settlement Outside the CPA}

Credit card networks, PayPal and similar online payments providers, and to some extent Interac e-Transfer, do not clear and settle over the CPA infrastructure.

For credit card payments, a merchant acquirer transmits a message over the credit card's proprietary network with the details of the payment. The credit card scheme, which holds settlement accounts, then adjusts the merchant acquirer's and the payer's bank accounts. The merchant acquirer makes funds available to the merchant. The payer's bank sends the payer a bill once a month. ${ }^{\mathrm{a}}$

PayPal and similar online payments schemes hold settlement, usually called "payment," accounts for their clients. When one PayPal client pays another, PayPal adjusts the payer's and payee's account balances in real-time to reflect the payment. To execute such a payment, however, the sender must either load funds from his/her bank account into PayPal, provide a credit card number for PayPal to charge or have sufficient funds from a previously received payment. It takes six to eight business days for funds to transfer from a Canadian bank into a PayPal account (paypal.com). ${ }^{\mathbf{b}}$

Acxsys Corporation, a subsidiary of Interac, administers the Interac e-Transfer service, providing a real-time communications network and netting between banks. The e-Transfer works in the following way: upon an online transfer request by the payer, his/her bank sends an e-mail or a text message to the payee, who logs into his/her bank account online and deposits the transfer amount. ${ }^{\mathbf{c}}$ Banks settle over the LVTS at the end of day. Providers usually cap the daily Interac e-Transfers one client can send or receive at $\$ 3,000$, likely to prevent fraud. While e-Transfers are not currently a central payment instrument in the Canadian economy, their use is growing rapidly.

a The payer's bank, not the credit card scheme, provides credit to the payer. Credit card networks also settle transaction for their proprietary pre-paid and debit cards.

b Additionally, funds loaded to a PayPal account leave Canada's jurisdiction, which may hinder the enforcement of Canadian laws against money laundering and terrorism financing. PayPal users tend to keep low account balances in general (eBay annual reports), in part perhaps because PayPal has been known to freeze account balances to investigate potential fraud.

c Interac Online offers a service similar to an e-Transfer, but only for online retail payments.

BCL. ${ }^{9}$ The total value of transfers a sender is allowed to transmit to a receiver is capped by the BCL the receiver granted it plus any previous transfers from the receiver. Additionally, a participant's total net-debit to the system must not exceed 30 percent of all BCLs it was granted, combined.

9 Alternatively, each financial institution could collateralize its own transfers. However, this would result in every participant delaying its non-time-sensitive transfers until end of day, imposing additional costs on the payments system (Koeppl, Monnet and Temzelides 2008). 
Recall that a participant's LVTS-accepted transfer does not settle until the end of day, it is only netted out of incoming transfers. In case of a participant's default on its net-debit position, the Bank of Canada seizes the defaulter's collateral. If the defaulter's collateral is not enough to cover its net-debit position, the Bank seizes collateral pledged by those extending BCLs to the defaulter in proportion to the BCL's size. ${ }^{10}$ Thus, each participant has the ability to lower the BCL it grants to troubled institutions to reduce incoming transfers from them, and its exposure in case the troubled institution defaults.

\section{Automated Clearing and Settlement System (ACSS) ${ }^{11}$}

Established in 1984, the ACSS initially processed all transfers between participating banks until the LVTS was introduced in 1999. Today, the ACSS processes only low-value transfers, mostly due to payment orders by clients, including retail payments, and most business-to-business payments. It does not operate under the SWIFT standard, and its ability to transmit remittance information is severely limited. As I explain further below, payers usually use an external system to transmit remittance data.

ACSS direct participants, called "direct clearers," submit transfers mostly at the end of the business day. At that time, the system computes each direct clearer's net-debit positions and communicates these to all direct clearers and the Bank of Canada. Clearers then settle obligations the next business day by transferring the funds they owe over the LVTS to the Bank of Canada. The Bank adjusts direct clearers' settlement accounts.

The ACSS does not require collateral because its transfers are of lower value. In case of default by an ACSS direct clearer, the surviving clearers share the defaulter's obligations proportionally to the transfers they received from it during the day. ${ }^{12}$ Unlike the LVTS, however, they have little ability to limit these transfers and, hence, their exposure to the defaulter could be high. While most direct clearers are unlikely to fail as a result of one ACSS clearer defaulting, the risk of losses is rather substantial, stemming mainly from inability to control exposure or implement other risk measures, since no clearer observes its net position before end of day.

\section{How to Improve Efficiency}

The Canadian economy would benefit from an upgraded payments system that creates lower financial risk, lowers payment-processing costs for businesses and, as a consequence, makes Canadian businesses more competitive globally.

\section{Reducing Financial Risk}

Payments systems that do not settle in real time create claims of one participant on another - net-debit positions held until settlement. If the party on which claims are drawn defaults, those participants holding the claims suffer losses. Both the IVTS and the ACSS clear with a delay and, thus, expose participants to the risk of loss in case of default - counterparty risk. High risk is not conducive to economic activity. Bank executives are usually held responsible by shareholders for losses, thus their fear of this outcome could make them more hesitant to

10 If more than one direct participant defaults on its LVTS obligations, the Bank of Canada guarantees settlement.

11 The exposition in this section is largely based on Northcott (2002) and Dingle (2003).

12 See http://laws.justice.gc.ca/eng/regulations/SOR-2003-346/page-10.html\#h-29. 
undertake risky, but otherwise profitable transactions. While risk can be sold to a third party for a fee, such a fee raises the cost of doing business, which also reduces economic activity.

ACSS technology does not allow participants to manage risk actively throughout the business day, as it does not provide information on each participant's net positions until day's end. In contrast, the LVTS real-time data transmission and positions-updating capability make participants fully aware of their net positions at every point in time and allows them to actively manage risks. Additionally, the BCL feature of the LVTS allows for controlling exposures to troubled participants, thus reducing the counterparty risk. The LVTS mitigates the counterparty risks reasonably well. Real-time data processing is significantly cheaper today than it was in 1999, making it more viable to channel lower-value payments also through the LVTS, even if it implies a significant increase in LVTS volume of transfers. This militates for abolishing the ACSS and processing all Canadian dollar inter-bank transfers through the LVTS.

\section{Lowering businesses payment-processing costs}

Businesses usually deal with multiple suppliers and consumers simultaneously, and receive and make payments from and to all of these. Therefore, to process each payment correctly, businesses require information as to what item the payment applies. Such information is called remittance data. Remittance data allows businesses to update their accounting books correctly and verify all payments received. For example, a utility cannot post billpayment confirmation to a customer's account until it processes all the remittance data. When both payment and remittance data are processed the utility updates its books.

Most business-to-business payments occur through cheques and EFTs and settle over the ACSS. The ACSS provides no remittance information in its EFT stream and severely limited information in other streams. Any business wishing to receive an EFT with electronic remittance data must contract with a payments-service provider. Payments-service providers generally are not direct clearers in the ACSS ${ }^{13}$ - hence, every EFT a business receives implies an involvement of at least two separate firms and two separate communication systems - one for the payment and one for the remittance data (CPA 2008). ${ }^{14,15}$

Remittance-data providers typically do not offer a uniform standard for data transmission. If they offered enough remittance data, a business could, in principle, update its books automatically and within seconds, eliminating the costs of manual accounting-related payment processing. To do this, the business needs to invest in proper IT infrastructure. The more steps of book updating a business automates, the costlier is the investment. Due to lack of common standards, a business's internal IT system that talks to one remittance data provider may not talk to another.

Therefore, if a business wants to change its provider or pay a new supplier who uses a different standard, it would have to update its IT infrastructure yet again - another costly process. For this reason, businesses have

13 To become a direct clearer in the ACSS a participant must account for at least 0.5 a percent of the ACSS clearing volume and have a settlement account at the Bank of Canada, see http://www.bankofcanada.ca/core-functions/ financial-system/oversight-designated-clearing-settlement-systems/canadas-major-payments-systems/.

14 The number of possible intermediation structures is virtually unlimited. Consider three cases as examples: 1) one non-bank provider offers the entire package to the end-user, 2) the user contracts separately with a remittancedata provider and a funds-transfer provider and 3) the user's bank provides both. For case 1, the provider contracts separately with a bank and another firm that offers remittance data, or offers remittance data itself. In case 3 , the bank usually contracts out the remittance data service, but clears directly with the CPA.

15 While the situation may have changed since 2008, I am unaware of any more up-to-date studies examining the issue. 
little incentive to automate their accounting systems. On the other hand, once an appropriate IT investment takes place, the cost of processing each payment drops substantially. Hence the lack of a uniform standard hurts the efficiency of payments processing.

Since most banks and remittance-data providers specialize in re-occurring bill payments and price accordingly, smaller businesses often find the most economical approach is to initiate and accept cheque payments, especially for one-off payments. But cheques severely limit the automation of accounting and add more processing costs because they must be handled manually. Cheques also pose environmental costs through paper and ink use, as well as vehicle emissions in deliveries.

The LVTS already provides some remittance data in the standardized SWIFT format. Indeed, this format allows businesses to automate the accounting function. Thus, if all transactions switched to the LVTS, and the banks forwarded the LVTS data packages directly their business clients, businesses would be able to buy offthe-shelf compatible accounting software and save both on IT development costs and on payments-processing costs. Moreover, the CPA is currently upgrading its data standards to be fully compatible with the International Organization for Standards (ISO) 20022, a remittance-data standard that will allow even higher data volume and faster processing. ${ }^{16}$

The most common use of the LVTS is for inter-bank transfers. However, upon request and for a fee, banks wire payments in SWIFT format on behalf of customers over the IVTS. Why don't banks today channel all payments through the IVTS?

Currently, every LVTS transfer, due to collateral requirements, imposes significant costs on participants. Tranche 1 transfers require full collateralization. For Tranche 2 transfers, if a bank uses some of the BCLs it was granted on its clients' transfers, it would have less available for its own planned transfers. Collateral, which participants pledge to the LVTS, is tightly managed since maintaining excess collateral is costly. When a business requests a wire transfer, it could be costly for its bank to pledge required collateral for a transfer in Tranche 1, or delay already planned transfers in Tranche 2. Thus, banks have an incentive to charge high fees for the wire service.

Today, the payer's bank cannot guarantee the total cost of a wire transfer, as intermediaries and the receiving bank collect their own fees. All fees are deducted from the transfer amount, which makes the final payment sum uncertain. ${ }^{17}$ Eliminating collateral requirements for low-value payments over the LVTS would reduce the incentive for banks to charge high fees for this service and allow more businesses to have consistent access to a fully automated remittance data network. This would make the costs of payments processing both lower and more certain. ${ }^{18}$

\section{Higher Competitiveness of Canadian Businesses}

Businesses in manufacturing and complex service industries, such as the financial sector, tend to organize in supply chains. Within a supply chain, the speed and reliability of payments between individual businesses determines the desirability of relationships, their profitability and the total costs of a supply chain's output.

16 See https://www.cdnpay.ca/imis15/eng/Publications/News/eng/res/ns/ISO_20022_overview.aspx.

17 For example, see http://www.rbcroyalbank.com/products/deposits/wire-payments.html, specifically footnote 17 at http://www.rbcroyalbank.com/products/deposits/_assets-custom/terms.html\#17.

18 As long as there exists the practice of charging fees to the principal in wire transfers, issues regarding accuracy of payments received will arise. Lower costs from the banks' perspective of LVTS low-value transfers will reduce the scope of the problem. Additionally, the practice might change if the number of wires demanded rises under the new system. 
The Canadian economy benefits greatly from parts of global supply chains that are located within the country. Canadian members of global supply chains generate jobs and tax revenues. Since payments are a cost to running a business, lowering them will encourage more contracts among existing businesses, more entry and job creation and lower overall costs of Canadian output. Lower costs will increase global competitiveness.

It is important to emphasize the need for speedy payment processing in business relationships. Because all payments that banks transmit through the ACSS settle the next business day, receiving banks are exposed to the risk of the payer's bank defaulting or refusing to honour the payments, if banks made funds available to the payee before the settlement occurs. Banks mitigate this risk in two ways: they delay the availability of funds for EFTs and Interac debit payments, and they leave the risk for cheques with the payee.

All LVTS transfers are final upon acceptance by the system. This finality eliminates the banks' incentive to delay funds availability, and if combined with real-time payer's funds verification, eliminates the risk of non-payment. Faster availability of funds, and eliminating the risk of non-payment through real-time verification could go a long way to spurring economic activity to the benefit of the Canadian economy. ${ }^{19}$

\section{The Need for Public Policy}

While the benefit of using more advanced technology to clear, settle, and transmit remittance data for low-value payments is readily recognizable, one could argue that the industry nevertheless practises efficient investment, given today's investment costs. But this is not a sound argument, due to the public-good nature of payments networks. $^{20}$

Payments system participants do not have an incentive to invest at a sufficient pace because they cannot appropriate all the benefits a payments network delivers - some of the benefits go to third parties. Banks, for example, cannot recoup their own investment costs from other banks' customers. At the same time, preventing customers of other banks from using the system decreases the benefits to a bank's own customers, also reducing its ability to generate a return on the investment. ${ }^{21}$ This reduces the incentive to invest in clearing and settlement infrastructure at a sufficient pace.

While the CPA (2008) review of bill payments and the Task Force for the Payments System Review (2011) conducted interviews with payments-industry participants, these studies did not make available the interview quantitative data. The qualitative results, however, suggest that users of the Canadian payments system, both businesses and consumers, perceive that their needs are not adequately met by currently available payments services.

19 One could argue that delaying availability of funds provides an opportunity for a payer to refuse payment if goods or services were not rendered as contracted - a benefit to society. For these purposes, however, other commercial arrangements exist, such as a money-back guarantee.

20 To be precise, a payments service is a "club" good - a type of a public good to which its provider can restrict access. In practical terms, however, a payments service becomes more valuable as the number of potential payers and payees connected to the service rises.

21 Crean (1996) believes that innovations in what was once a world-leading Canadian payments system (Crean1979) have slowed down since the CPA was created in 1980. He argues that the CPA structure, especially a 1996 seminal Competition Tribunal decision, now allows smaller financial institutions to free ride on the investments of larger institutions. Bergevin and Zywicki (2012) provide more evidence of slow investment in new technologies on the retail payment side. 
A similar review of the UK payments industry also suggested that the services available are not meeting the needs of its participants (Summers and Wells 2014). The UK report prompted a policy response that led to introduction of the Faster Payments Service (Summers and Wells 2014), which allows a low-cost funds transfer within seconds between most UK bank accounts. Providers usually cap payments at $£ 10,000$ for individuals and at $£ 100,000$ for businesses. ${ }^{22}$

\section{Policy Implications}

A conceptual difference between most of the world's large- and low-value inter-bank clearing and settlement systems is that the former process one transaction at a time, while the latter process batches of transactions at once, and net outgoing from incoming fund flows, within the batch, for each participant. If the large-value system is a Real-Time Gross Settlement (RTGS) system, such as the RTGS operated by the Bank of England, two types of costs, aside from collateral, are important: 1) liquidity, meaning maintaining dedicated funds to settle transactions as they arrive; and 2) communication and data processing costs. These costs have historically implied that batch delayed net-settlement systems were more suited to low-value, high-volume transactions than are RTGSs.

Since the LVTS in Canada does not settle in real time, but only at the end of business day, it is not an RTGS in this sense. Transfers one participant makes are netted from those it receives throughout the day, and the incoming transfers will reduce what the participant owes by the end of day. This creates considerable liquidity savings, which the Bank of England's RTGS, for example, does not offer. Still, there remain communication and data-processing costs, though these have fallen significantly over the past decade, as demonstrated by the ubiquity and pricing of cloud computing today. For this reason, batching transactions, only to save on data-processing costs, makes little economic sense.

The time has come for the CPA to discontinue the 30-year-old ACSS and merge lower-value payments into the LVTS. There are international precedents for this move, including Switzerland, where the same system clears and settles both low- and high-value payments (Bech, Preisig and Soramäki 2008).

The IVTS scheme allows its direct participants to manage risk better than the ACSS, even if one neglects the collateral aspect. In case of default, both systems impose costs on surviving participants proportional to the transfers they received from a defaulting participant. For the ACSS, however, the net positions are not known until end of day. Even if positions were known in real time, it is not clear how a participant could reduce incoming transfers from a troubled direct clearer beyond refusing them altogether.

Meanwhile, the LVTS updates information on all net-debit positions in real time. Additionally, not fully collateralized LVTS transfers require a prior BCL extended by the receiver. Thus, LVTS direct participants can reduce their exposure in case of default by reducing the BCLs they extend to troubled participants.

The IVTS is costly to use due to its collateral requirements. Collateral, however, is less important for low-value payments, as a default by one institution is less likely to result in others. The CPA, under the guidance of the Minister of Finance, should introduce a Tranche 3 option, where no participant needs to pledge collateral. ${ }^{23}$

22 See http://www.fasterpayments.org.uk/consumers/transaction-limits.

23 The CPA could consider renaming the LVTS - once it introduces lower-value transactions to the LVTS - to the High Speed Transaction System. 
However, participants should also extend BCLs for incoming transfers in Tranche 3 since these are an important tool for managing risk. To reduce financial risk further, the LVTS should impose a limit to each participant's permissible net-debit for transfers in the uncollateralized Tranche 3. If a participant needs to go beyond the limit, it would have to make a transfer in Tranche 1 or Tranche 2 to cover some of its accumulated net-debit in Tranche 3. This will keep the systemic risk in check. With these safety measures, the Bank of Canada probably need not guarantee Tranche 3, as it does with Tranche 1 and Tranche 2.

Removing collateral requirements for LVTS low-value payments will reduce bank wire-payment costs. Since the LVTS possesses real-time communications capability, transmits SWIFT remittance data, and will eventually meet the ISO 20022 standard for financial services messaging, it would be logical for it to handle all transactions and discontinue the outdated ACSS, rather than upgrade it. Moreover, to reduce payment-processing costs and improve businesses' international competitiveness, it is paramount to speed up the implementation of ISO 20022.

This policy recommendation would require the federal Department of Finance and the CPA to solve a number of technical issues. For example, the volume of transactions over the LVTS would increase substantially, ${ }^{24}$ which would require an investment by the CPA in its processing capabilities; additionally, an adequate limit to each participant's permissible net-debit in Tranche 3 needs to be determined to mitigate the costs of defaults.

Meanwhile, the ACSS currently offers a number of streams for payments and data formats. For example, some ACSS transfers are initiated by the payees, rather than the payer's bank - the so-called "pull" payments. The LVTS, on the other hand, offers one standardized type of payments in a uniform data format initiated by the payer's bank. This would require some adjustments in payments arrangements in the Canadian economy. ${ }^{25}$

I believe that banks, non-bank payments providers, as well as individual businesses, would have to adjust to the new system by making some IT investments and dealing with fraud in real time. On the one hand, this would imply a fall in demand for some existing services. On the other hand, this would create opportunities for banks and payments providers to offer new and profitable services. Overall, one standardized payments system would likely make easier both CPA's task of keeping up with needed upgrades and its members' task of agreeing on their implementation. Standardization of payments which flow over a unified modern and efficient clearing and settlement system would benefit the entire Canadian economy.

\section{Conclusion}

The CPA, under the guidance of the federal finance minister, should establish an uncollateralized LVTS Tranche 3 to process low-value payments with real-time, net-debit position updates to participants, immediate finality, and utilize BCLs to control risk. This would speed up the availability of funds for businesses, and provide them with standardized remittance data.

24 In 2013 the LVTS processed 7.58 million transactions (see http://www.cdnpay.ca/imis15/pdf/pdfs_publications/ stats_lvts_2013.pdf), while the ACSS processed 6.74 billion (see http://www.cdnpay.ca/imis15/eng/Publications/ Statistics/eng/res/acss_quarterly_stats_2013.aspx).

25 Any pull payment can be treated as a push one for the LVTS if the rules of payment entry change. For example, preauthorized debit can be provided by the payer's bank as a push service. A cheque the payee's bank receives eventually finds its way to the payer's bank. Currently, the payee's bank enters the cheque into the ACSS. Once the ACSS ceases operations, one could implement a new rule, such that the payer's bank enters the cheque into the LVTS upon receiving its digital image or physical copy. 
At the same time, the ACSS should be discontinued. Today, it provides information on direct clearers' net-debit positions only at the end of the business day and, therefore, produces neither adequate information nor tools for clearers to control their exposure to troubled institutions. The new proposed LVTS Tranche 3 would provide real-time information on each participant's net positions and with its BCL requirements will enable controlling exposure in case of defaults.

The IVTS already offers remittance-data transmission in a uniform SWIFT format. Making SWIFT data available for low-value transactions would allow businesses to invest in more accounting automation, reducing paymentprocessing costs. This also calls for a fast implementation of ISO 20022, which will improve remittance-data processing further.

With all low-value payments flowing over the LVTS Tranche 3, businesses' payment-processing costs will fall. Banks will have little incentive to delay the availability of funds, allowing businesses to conduct more profitable transactions and investments. All these developments would make Canadian businesses more productive and more competitive globally. 


\section{References}

Arango, Carlos, Kim P. Huynh, Ben Fung, and Gerald Stuber. 2012. "The Changing Landscape for Retail Payments in Canada and the Implications for the Demand for Cash." Bank of Canada Review. Autumn. Available at: http://www.bankofcanada.ca/wp-content/uploads/2012/11/boc-review-autumn12-arango. pdf.

Arjani, Neville, and Darcey McVanel. 2006. “A Primer on Canada's Large Value Transfer System.” Bank of Canada. March. Available at: (http://www.bankofcanada.ca/wp-content/uploads/2010/05/lvts_neville. pdf).

Bech, Morten L., Christine Preisig and Kimmo Soramäki. 2008. "Global Trends in Large-Value Payments." Federal Reserve Bank of New York Economic Policy Review. September. Available at: http://www. newyorkfed.org/research/epr/08v14n2/0809prei.pdf

Bergevin, Philippe, and Todd Zywicki. 2012. Debit, Credit and Cell: Making Canada a Leader in the Way We Pay. Commentary 353. Toronto: C.D. Howe Institute. June

Canadian Payments Association (CPA). 2008. "Issues Paper: Review of Bill Payments in Canada." Policy and Research Division. February. Available at: https://www.cdnpay.ca/imis15/pdf/pdfs_publications/ bill_payments_issues_paper_2008.pdf.

2013. “LVTS Rules Overview.” April. Available at: https://www. cdnpay.ca/imis15/pdf/pdfs_rules/lvts_rule_overview.pdf.

Crean, John F. 1979. "Automation in Canadian Banking: EFTS and the Public Interest.”Toronto: Canadian Bankers Association.

1996 "Issues in Canadian Payments System." In The Regulation of Financial Institutions, Queen's Annual Business Law Symposium, pp. 463-472.

Dingle, James F. 2003. Planning an Evolution: The Story of the Canadian Payments Association, 1980-2002.

Bank of Canada and the Canadian Payments Association. May. Available at: http://www.bankofcanada. $\mathrm{ca} /$ publications/books-and-monographs/planning-an-evolution.

Engert, Walter, Toni Gravelle and Donna Howard. 2008. "The Implementation of Monetary Policy in Canada." Discussion Paper 2008-9. Bank of Canada. July.

Koeppl, Thorsten, Cyril Monnet and Ted Temzelides. 2008. "A Dynamic Model of Settlement." Journal of Economic Theory 142(1): 233-246. September.

Northcott, Carol Ann. 2002. "Systemic Risk, Designation, and the ACSS." Financial System Revierw. Bank of Canada. December. 29 - 35. Available at: http://www.bankofcanada.ca/wp-content/uploads/2010/05/ report.pdf. 
Schembri, Lawrence. 2014. “A Dual Vision for the Canadian Payments System.” Remarks by Deputy Governor of the Bank of Canada for the Canadian Payments Association Conference. Charlottetown. June. Available at: http://www.bankofcanada.ca/2014/06/dual-vision-canadian-payments-system.

Summers, Bruce J., and Kirstin E. Wells. 2014. "Governance of payment systems: A theoretical framework and cross-country comparison.” Mimeo. Available at SSRN: http://ssrn.com/abstract=2476552.

This E-Brief is a publication of the C.D. Howe Institute.

Mati Dubrovinsky is a Senior Policy Analyst at the C.D. Howe Institute.

This E-Brief is available at www.cdhowe.org.

Permission is granted to reprint this text if the content is not altered and proper attribution is provided. 